\title{
Relational social capital: Norwegian women's experiences of the process of being on sick leave and the path back to work
}

\section{Liv Johanne Solheim}

Faculty of Education and Social work Centre for Innovation in Services

Lillehammer University College

Email: liv.solheim@hil.no

\begin{abstract}
Background: The reduction of the number of people that drop out of the labour force and temporarily receive public benefits has increasingly been a political priority in Norway since the early 1990s. In particular, there has been a focus on reducing sick leave. However, none of the efforts in this direction has had the desired effects. To succeed, more knowledge is needed regarding the factors that create the illnesses influencing the length of the sickness leave.

Aim: The purpose of this article is to study how relational social capital, both at work and home, has an impact on the experience of being on long-term sick leave and the process of returning to work.

Methods: Individual in-depth interviews have been performed with 20 women between 25 and 60 years old. They were all sick-listed for more than 30 days during 2013 with mental illness or musculoskeletal diagnoses.

Results: The study illustrates how long-term sickness absence can threaten the identity and self-confidence of the sick-listed persons. The effects of relational social capital are expressed through personal relationships with their family members, friends, colleagues, and managers at their workplace. Individuals with high social capital in both the workplace and the domestic sphere have the best prospects for recovering and returning to work. High workplace capital may, to a certain degree, compensate for low domestic social capital. Single mothers with low social capital both in their domestic life and in their workplace are the most vulnerable.
\end{abstract}


Conclusion: Relational social capital influences both the experience of being on sick leave and the process of returning to work. The efforts to reduce sickness leave should therefore focus on not only the sick-listed person, but also their relationships with their family and in their workplace, as well as the interplay between these.

Keywords: Sickness absence, relational social capital, women, mental illness, musculoskeletal diagnoses

\section{Introduction}

During the last few decades the relation between social capital and health has been extensively explored (Kawachi et al., 2008; Berkman \& Glass, 2000; Lomas, 1999), and social capital has become a popular theory through which differences in health and illness between social groups can be explained (Turner, 2003). Social capital is often viewed as both an individual (Bourdieu, 1986; Coleman, 1988) and a collective characteristic (Putnam, 1993, 2000). A social-capital perspective applied to health presents a view that the quantity and quality of the relationships of a collective or a person play a role in the maintenance of health, and, at the same time, may provide useful resources during the recovery from illness.

Social capital generally has positive connotations. However, supporting networks may also have negative effects, such as exclusion of outsiders and demands for conformity that may be experienced as restrictions upon individual freedoms (Portes, 1998). Investigating the experiences of individual social capital may uncover nuances in the experiences of different aspects of social capital. In this article, social capital is viewed as resources accessible to individuals by their involvement in social networks in their private lives and in their workplace. Access to individual social capital is expected to influence their experience of being sick-listed and the prospects for returning to work.

A systematic literature review of the connection between social capital and health found significant correlations between the two in individual- 
level studies. These studies showed that social capital, when viewed as individual characteristic, could contribute to the field of health promotion (Eriksson, 2011). In contrast, studies investigating the link between collective social capital and health show inconclusive results. $\mathrm{Kim}$ et al. (2008) conclude that the strongest associations are between individual social capital and health, particularly between cognitive components of social capital and self-related health.

There are different perspectives from which illness and sickness absence can be understood. The bio-medical model focuses on individual risk factors and tries to find exact indicators for different diagnoses. The socio-cultural model focuses on people as cultural and social beings, and in this model illness has to be understood in relation to the life situation of the individual (Gannik, 2005; Verdonk et al., 2008; Rønning, 2011). Consequently, because illness is influenced by the afflicted individual's surroundings, it can change correspondently with changes in their life situation - health problems might be reduced or cured by changes in their social relationships or environment. This may be particularly important in relation to mental and musculoskeletal problems because the symptoms are often diffuse and difficult to document, and therefore it is also difficult to determine an exact diagnosis and appropriate treatment (Steihaug, 2007). In this way, the socio-cultural model may be an important supplement to the dominant bio-medical model. In this article, I have adopted a social constructivist perspective, which is also the basis of the socio-cultural model. Employing this perspective, I shall not draw objective conclusions but instead attempt to understand how people interpret themselves and their situations.

Mental illness and musculoskeletal problems are the most common diagnoses for sick leave among women in Norway. The aim of this article is to explore how women diagnosed with mental illness and musculoskeletal problems experience the challenges connected to staying in the work force, and, in particular, how individual social capital influences both the experience of being on long-term sick leave and the prospects of returning to work.

In line with the tradition deriving from Bourdieu and Coleman, several studies about individual social capital and health have focused on social capital and social networks in local communities. Some of these studies indicate a significant gender difference. One example of this is a Swedish study (Eriksson 2011) which shows that women are more likely than men to have access to bridging social networks. Another is 
a study of community network in England that finds that women are more involved in face-to-face local networks, while men are more involved with non-local networks (Campbell et al., 1999).

Other studies have focused on the relationship between employees' health and factors at the workplace including, specifically, healthpromoting factors. A prospective cohort study of middle-aged French employees (Melchior et al., 2003) has concluded that the quality of the work environment and the quality of social relations exerted independent effects on the incidence of sickness absence in the target population over a six-year period. Another study performed by Oksanen et al. (2008) has found that social capital at work was a predictor of health in a cohort of initially healthy local-government employees. This study supports the hypothesis that exposure to low social capital at work may be detrimental to the health of employees. Increasing levels of individual social capital were associated with sustained good health. However, the findings of another prospective cohort study - in this case of public-sector employees in Finland suggest only partial support for the hypothesis of work-related social capital as a health resource (Liukkonen et al., 2004).

A few studies have focused primarily upon factors in domestic life. Mamun et al. (2009) have investigated the bi-directional association between symptoms of depression and quality of marital relationship in a population-based cohort of women. The study suggests that symptoms of depression and quality of marital relationship are strongly associated with each other and that this association is bidirectional. Staland-Nyman et al. (2007) have found an association between domestic job strain and self-reported health, and the relationship was strongest for the dimensions that measured psychological health. Another example is a study by Østlund et al. (2004) that shows that the domestic arena is crucial in rehabilitation after sickness absence, and indicates that domestic strain might influence both the length of the sickness period and the decision to return to work.

Long-term sick-listed women are in a vulnerable situation. They do not know how long they are going to be sick-listed or if they will be able to go back to work. For some this may be a crossroads in their lives. A study by Ockander and Timpka (2003), focusing on how women handle and explain this interruption of their daily lives, distinguishes between three different groups. The first group is characterized by feelings of hopelessness and of being pushed away. The second 
group is characterized by the conflict between having the power and initiative to plan their future back to work and a feeling of resignation. The third category was characterized by migration away from the workplace and consisted of women who had no plans for returning to work. Another study (Eriksson \& Janson, 2013) has identified four different groups in relation to the work strategies as a norm: the returners, the reoriented, the ambivalent, and those who had given up. These studies show that being long-term sick-listed challenges women's identities, and illustrate how the construction of identity is influenced by individuals' social context (Goffman, 1961; Järvinen \& Mik-Meyer, 2003).

Since the early 1990s, there has been a growing body of literature focusing on the relation between individual social capital and health. However, within this literature there is a lack of studies that utilize a holistic approach to examine the subjects' total situation, including all the different roles they have to combine (Solheim, 2011). The women in these situations have varying roles in their domestic lives (as mother, wife, daughter, and friend), in their working lives (as employee), and as sick-listed individuals (as patient). Social capital potentially has an impact at their workplaces, in their families, and in their neighbourhoods, and in the interplay between work life and domestic life.

The ambition of this study is to contribute to addressing some of the gaps in knowledge in this area. The research question is as follows: In what ways do work-related and domestic social capital influence the experience of being on sick leave and the prospects of returning to work for long-term sick-listed women? The study will explore the significance of long-term sick-listed women's relational social capital, in both domestic and work-related situations, for their health and for their prospects for returning to work. Domestic social capital affects relationships with family members and potential relationships with friends and neighbours. Work-related social capital involves relationships with colleagues and leaders in the workplace. In the next section, I shall introduce the perspective of relational social capital and present some relevant literature.

\section{Relational social capital and health}

Social capital is defined in different ways, but there is a distinction of primary importance made between social capital as an individual 
asset and social capital as a collective attribute (Eriksson, 2011). Esser (2008) has used the concepts of system capital and relational capital to make a distinction between these two aspects of social capital. System capital is explained as a collective good and an aspect of the organization of a community. A community's health service and rehabilitation systems may be considered components of system capital. Relational social capital is regarded as an individual's personal social resources. Trust and obligation are important aspects of relational social capital. Trust capital is the resources and benefits an individual can activate because of his reputation of being trustworthy. Obligation capital refers to the agreements between individuals and the resources these can activate. These kinds of agreements can only function if there are mutual interests in the relationship. In this article, the focus is primarily on how relational social capital influences the experiences of the sickness-absence period and the prospects for returning to work for long-term sick-listed women.

An individual's total amount of relational capital represents the sum of all the resources and benefits on which the individual can draw because of direct or indirect relationships with other individuals. The values of these resources are dependent upon earlier investments, and in this way relational capital may be regarded as a form of saving (Esser, 2008).

The relation between social capital and health has been studied in a public-health perspective (Kawachi et al., 2008; Lochner et al., 2003, Berkman \& Glass, 2000; Campbell et al., 1999, Berkman \& Syme, 1979). There is also an extensive field of studies that have focused on the association between individual social capital and health. Finnish studies (Hyyppä \& Mäki, 2001, 2003) show that a great deal of health equality between Swedish-speaking and Finnish-speaking individuals living in the same Finnish regions can be explained by differences in social capital. This is confirmed in a nationwide survey of the two language groups (Nyquist et al., 2007). Verhaeghe et al. (2012) have examined a representative sample of adults from the Belgian population. The aim of their study was to examine whether there was an association between network social capital and self-rated health after controlling for social support. Their findings indicate that social networks from the working class could offer people fewer healthbenefiting resources than those from the intermediate or higher service class. This is a reminder that social networks may have different qualities and different contributions to social support, and 
they may have different effects upon health. A cross-sectional study in northern Sweden (Eriksson et al., 2010) has aimed to study the links between individual social capital and self-rated health between men and women and between different educational groups. The findings show that access to social capital can partly explain the health inequality between men and women and between different educational groups.

The relation between social capital and mental health is complex. Studies show that social capital contributes to reducing depression related to life crises (Brown \& Harris, 1978). However, not all close relationships have a positive effect on health. It is therefore not sufficient only to study the amount of social capital; the quality of the relationships must also be considered. Portes (1998) makes a distinction between sources and effects of social capital.

Rose (2000) has found that both human capital (age, social status, gender, and income) and social capital (involvement in or exclusion from formal and informal networks) are major determinants of health. Human capital is here defined as characteristics of the individual while social capital is connected to the individuals' social networks. His study shows that social capital makes an independent contribution to health, and that it increases physical and emotional health more than human capital. The work of Eriksson et al. (2011) also shows a positive association between collective social capital and self-rated health for women but not for men. Others have studied how people cope with stressful life events and uncovered the need to take into account the social capital available to different groups. One example is the study by Garret-Peters (2009) that shows that social capital is important for coping with the loss of a job. The following section will introduce the methods of the current study as well as a presentation and discussion of the data.

\section{Methodological approach}

This article is based upon data collected as part of the project 'Social factors contributing to sickness absence' (SOFAC). This project includes different comparative studies between Norway and Sweden using both qualitative and quantitative methods. The first part of the project consists of qualitative studies of sick-listed men and women in both countries. This article presents the results from the Norwegian study among sick-listed women. 
This study has an exploratory approach focusing on the kind of knowledge used in everyday life (Berger \& Luckmann, 1967; Wagner, 1983). The data were collected with an open mind in order to record the informants' experiences in their own terms. We covered four topics in all the interviews, but we did not formulate the specific questions in advance in order to apply the flexible approach to each interview. The study adopts the central method of symbolic interactionism, which seeks to understand the phenomenon from the informants' perspectives and to describe their experiences. In addition, the study has been inspired by grounded-theory approach (Glaser \& Strauss, 1967; Glaser 1998) and has sought to come up with more abstract conceptualizations of the role of relational social capital for experiences of being on sickness leave and prospects of returning to work. In the analysis of the data the respondents are classified in four different groups on the basis of their own descriptions and experiences of the amount and quality of their domestic and workplace social capital.

The interviews were conducted in the spring of 2010. The respondents were asked where they wanted to meet the interviewer. Some of the interviews were conducted in the respondents' homes, some at the local college, and some in a room rented at the local library. The interviews were tape-recorded and transcribed. Batt-Rawden and Solheim (2011) have given the first presentation of the material and a more extensive presentation of the methods used. The analysis began with open coding in order to capture the concepts, themes, and statements that were central in the subjects' descriptions. In the next stage of selective coding, we limited the categories and showed the dimensions representing the variations within the data. Finally, we examined the data to identify themes, to explore categories, and to develop concepts.

The study is based upon a sample of long-term sick-listed persons' own explanations and understandings of their sickness absences. These absences are all due to mental problems or musculoskeletal problems, the two most frequent groups of diagnoses among people on sick leave in Norway. With both of these diagnoses, it is often difficult to find objective symptoms, and the problems presented often have complicated backgrounds. In addition, these groups frequently overlap. 
The informants were contacted according to the instructions set by the SOFAC project in accordance with the Regional Ethical Committee (REK). The department for statistical analysis at the Norwegian Labour and Welfare Service (NAV) selected a sample of 260 women and 260 men diagnosed with mental illness (ICPC-codes: P76, P02, A04) or musculoskeletal illnesses (ICPC-codes: L03, L84, L02, L18, A01, L92). The sample included people between 20 and 60 years old who were, or had been, long-term sick-listed for at least 30 days during the previous year. To reduce the travel time, the sample was limited to subjects in 10 municipalities in one Norwegian county. The purpose was to find a broad representation of men and women of varied ages and in different life situations. A letter was sent to the members of the sample group with information about the study. To comply with rules concerning anonymity, NAV sent the letter and asked informants to contact the researchers themselves about participation in the study. In total, 30 informants, ten men and 20 women, made contact and were interviewed. The initial aim was to gather a sample of 20 women and 20 men. In this article, only the women are included because we wanted here to focus on variations among the women.

The low response rate might have been connected to the procedure of selection, which relied heavily on the informant's initiative. Owing to ethical guidelines, NAV was required to distribute letters that provided the necessary information to potential informants, and then it was up to the informants to initiate the first contact with the researchers. Another reason might be that the group asked to participate may contain people who suffer from serious illness, and they might lack the motivation, the strength, or both, to participate. We do not know the reasons why so many declined to participate in this study, but there were certain revealing characteristics of the group that was willing to share their experiences. While most of them have had long-term and repeated experiences of being sick-listed for several years, at the time of the interview they had recovered and they often were willing to participate because they had experiences from their period of sickness absence that they wanted to convey.

\section{Characteristics of the sick-listed women}

Among the women, nine of the 20 had diagnoses related to mental problems. In addition, four of the women with musculoskeletal issues also had a recent history of mental problems. This is an example of 
the frequency of the overlap between the two diagnoses. The women in the sample are relatively well educated: 12 have higher education, four have vocational education, and four have basic education. Two of the women were in their twenties, three were in their thirties, eight were in their forties, and seven in their fifties. For most of them, their illness had developed over the course of several years, and the majority had been long-term sick-listed two or more times before.

\section{Results}

Being on long-term sick leave involves a break in daily life routines, and studies shows that the length of the sickness-absence period has an influence on prospects for returning back to work. This may indicate that being sick-listed may have an influence upon identity. The first part of this section will present the experiences of the women in this study. The next part will give a picture of the variations in the women's experiences with relational social capital in the domestic sphere as well as in the workplace.

\section{Identity at a crossroads}

Long-term sick-listed women identify themselves in different ways, and they have varied motivations related to returning to work. They face a choice of paths, where one road leads toward the pension system, another back to work, a third to part time work, and a fourth to a new, different career (Ockander \& Timpka, 2003; Falkdal et al., 2006).

In this study, most of the women in the sample still identified strongly as working people and had an active desire to return to work. Consequently, their focus was mainly on how to manage this. The long-term period of sickness absence had not changed their identity as working women, but had challenged it. One expressed her despair in this way: 'It is a desperate situation in that my body cannot keep up any more and my brain wants to do so much more than my body.'

Many women mentioned two experiences: a loss of self-confidence and uncertainty in relation to the prospects for the development of their illnesses and their future health. Since they had a strong identity as working women, their feelings of self-worth are eroding, along with their connectedness to their job communities. One woman expressed it in this way: 'My aim is to return to work. But now I don't know if it is 
possible. What pains me most is the uncertainty.... The uncertainty makes me depressed.' Another woman said: 'Without doubt my selfconfidence has been struck. It is like living on another planet - not to be part of the community.'

The women sometimes described the correspondence between their uncertainty and their self-confidence. One of them expressed it this way:

My job has been very important for me... You wonder if you will be able to return to your job. You are losing your self-confidence and feel you are less valuable... In addition, it is the uncertainty: that you in your young age will not be able to work - the horror scenario is to be a disability pensioner.

During the sickness-leave period, relational social capital may influence recovery and prospects for returning to work in different ways. Different aspects at their workplace and in their domestic life have an influence on the ways the individual women cope with the challenges connected to the situation of being sick-listed. The following section will present the ways in which the effects of relational social capital came to be expressed.

\section{Relational social capital experiences}

Women on sick leave experienced significant changes in their everyday lives. They were no longer employees going to work every day, with routines in their domestic lives adjusted to working hours. They now had other needs for support and community. One woman described the significance of relational social capital in this way:

The social relations you have are very important - that you have a social network. Many sick people are lonely, and then the problems may increase.... When you are frustrated and have pains, it is your social network that helps you to not give up.

There are variations among the women in the amounts of workplace and domestic capital they experience. Figure 1 illustrates the connection between these actors and gives a picture of these variations. 
Figure 1: Interplay between workplace and domestic social capital

\begin{tabular}{cccc}
\hline & & Workplace Social Capital (WSC) \\
& & High & Low \\
$\begin{array}{c}\text { Domestic } \\
\text { Social Capital } \\
\text { (DSC) }\end{array}$ & High & well connected & domestic \\
& Low & connected (3) & workplace \\
& & connected (3) & unconnected (7) \\
& & & \\
\hline
\end{tabular}

The total amount of social capital is dependent upon both workplace capital and domestic capital. The figure above illustrates that there was an accumulation of cases at both ends of the scale. Approximately one-third of the women had high workplace capital and high domestic capital, and about one-third had low workplace capital as well as low domestic capital. The classification is a result of the women's own descriptions, and is made based on the variations within this sample. Classification as high or low is therefore not based upon objective measures of high and low but upon the level or amount of social capital experienced by the women interviewed in this study. There are some smooth transitions between high and low social capital. I thus classified each woman on the basis of the group they best resembled.

The women who are classified as having high workplace capital had a positive relation to their workplace at a general level had social relations characterized by trust and social support with at least two or three of their colleagues, and had relatively close contact with the workplace during the sickness-absence period. The quality of the relations was characterized by trust and the relations with the workplace were important as social support. The group with low workplace social capital had a more distant relation to their colleagues and leaders during the sickness-absence period, and they lacked social support from the workplace. The women classified as having high domestic social capital had two or three persons whom they trusted and whom they could talk with confidentially. Most important for most of these women was a partner who was supportive and who 
took responsibility for tasks that the sick-listed women were unable to manage. Both social and practical support were necessary to be classified as having high domestic social capital.

One important aspect of domestic social capital is having persons in the domestic sphere who can give practical help and emotional support during the process of recovering from sickness and building self-confidence. Having high domestic social capital in this case means that there were at least two or three confidant and trusted people among the woman's family and friends who supported them emotionally, and with whom they could talk confidentially. Those who had fewer than two confidant persons around them and expressed dissatisfaction with their lack of a social network were classified as having low domestic capital. According to the sick-listed women's descriptions, the quality of their social relationships was much more important than the quantity.

The attitudes and norms in the local society may also be seen as aspects of domestic social capital. The surrounding neighbourhood could potentially provide support when needed. However, in this study, only a few of the women had close friends in their neighbourhoods and they only rarely experienced the neighbourhood as a supportive arena during the sickness-absence period.

Being classified as having high workplace social capital means that the woman had a trusting relationship with her leaders and colleagues and that she had regular contact with the workplace during the sickness-absence period. Women who had a distant relationship with their workplace and who expressed dissatisfaction with that relationship were classified as having low workplace social capital. Domestic and workplace social capital have independent influences on the experience of being long-term sick-listed, but there may also be some interplay between the two.

\section{High DSC and high WSC: the well connected}

The women who had both high workplace social capital and high domestic social capital had the best prospects for support in their rehabilitation. For these women, their relationships with their leaders and particularly their work colleagues played an important role during the sickness-absence period. Most of the workplaces had established routines for following up and keeping in contact with sick-listed 
employees. The women in these situations regularly had meetings with their leaders to discuss their status and what the workplace could do to reduce the sickness-absence period. Most of the women appreciated this contact.

The sick-listed women's relationships with their colleagues were also of great importance. Some of the women had strong informal relational ties with their co-workers, who became an important source of support during the sickness-absence period. These women often visited the workplace to meet with their colleagues, among whom a few of them had their best friends. One woman said, 'My colleagues are contacting me all the time, my leader has visited me several times, and they call me, send sms's and invite me for lunch.' In this way, contact with colleagues was important as a social arena. The workplace was often an extended space in these women's lives; here they had not only their work, but also close friends - and for some their closest friends.

The women's relationship with their workplace during the sicknessabsence period was important because it often sent signals - for example, a wish to come back to work, on the women's part, or, from the workplace, that the women were appreciated and wanted back, and that their presence (or lack thereof) made a difference. It was important that the leaders in the workplace gave such signals, but occasionally they also came from colleagues. Such reactions from the women's colleagues could be just as influential in motivating them to return to work as the signals from the leaders.

The experience of being long-term sick-listed sometimes leads to isolation, a feeling of loneliness, and a lower capacity to perform and participate in daily tasks at home. In addition, there may be feelings of uncertainty about the recovery of one's health, and what to do to stimulate the rehabilitation process. In this situation, it was important for the sick-listed individual to have people in their social network who understood their situation and their worries, and it was of vital significance that these people were available when there was a need to talk about the situation or when help was required. Some of the women in the sample needed relief with their daily tasks at home, and it was important for them to have somebody to turn to when they needed help.

Those who are classified as having high domestic social capital usually had a partner supporting them practically and emotionally. For 
some, this was an unusual situation because their partners were not used to doing all the housework or to seeing what needed to be done. Therefore the women sometimes had to take on the role of the administrator.

The women also described how the situation wore them down over time. One of them described the emotional exhaustion between her and her partner: 'My husband is the person I talk most with about my situation. But you know - he gets tired of talking about it -it's like that for me, too.' When their health problems lasted for a long time and there was little progress, a kind of resignation set in for both the women and their partners.

A few of the women talked about help and support they received from their extended families. More often, they had a few close friends from whom they received support. They would get together with these friends to talk about their situation, to focus on things other than their problems, or to participate in activities as a way to get away from what was sometimes a boring everyday life.

\section{High WSC and low DSC: the work connected}

For these women, the rehabilitation process was vital. However, this process was often impeded by a lack of practical support for tasks in the home and a lack of emotional support in their struggle for selfesteem. A common characteristic of this group was their satisfaction with the amount of contact and support they received from their workplaces. They had no complaints about their leaders or colleagues, even if some of them had limited contact with the workplace.

The main problems for these women were that the burdens of housework and childcare were too much in relation to their health problems and that they suffered from a lack of emotional support. Consequently, a low level of domestic social capital was deemed a hindrance to recovery due the lack of necessary emotional and physical support.

Some of these women were living with a partner, and while they appreciated any emotional and practical support given by a partner, some limitations were described. One of these women said: 'My 
partner is not good at conversation - he is a "thinker". But he does all I ask him to do in the household.'

This woman was living with a partner at the time, but she had been a single mother for many years. In addition, her children had health difficulties, one of them having developed drug problems at an early age. Her domestic situation had therefore been a burden, but she had been at work for several years with few sickness-absence periods. However, over the past few years, she had developed complex health problems, and at the time of the study, she had been sick-listed for months. During the years she had spent living as a single mother, she had used all her strength to keep up with her job, and she felt she was successful in her work and that she had good relationships with her colleagues. However, in her domestic life she was isolated. She had little contact with her neighbours and few friends in her surroundings. Everyone in the community knew about her son's drug problems, and her imagination about what people said about her as a mother was one reason that she avoided going to public places. In this case, the high workplace social capital partially compensated for low domestic social capital, and this woman actively connected with the workplace, even while she was sick-listed. This was her successful arena, and therefore it was important for her to continue working.

Neighbours or friends could potentially supplement low practical and emotional support from families. However, the women in the study showed a tendency to isolate themselves in their homes during the sickness-absence period. For some of the women, taking a walk during the day was important, but the walking route was planned in such a way as to decrease the chance of meeting people they knew. One example of this was a woman who worked in a pre-school. She did what she could to avoid walking in the area where the families who had children in her pre-school lived because she was afraid to meet the parents. Going shopping was another challenging situation. She described it in this way:

It has happened that I have been in the city and if I saw parents of the children I hid behind a shelf or went into a shop to avoid meeting them - especially if it was from my class - I know they are wondering and want to know.

The interviews show that for women with a low amount of domestic social capital it is of great importance to have an inclusive work place that they can visit even during the sickness-absence period. High 
amounts of workplace social capital may in some cases be the deciding factor in the ability to return to work. However, in most cases, high workplace social capital cannot totally compensate for a lack of social capital in the domestic sphere.

\section{High DSC and low WSC: the domestically connected}

These women usually had a partner who shared the responsibilities for their practical everyday duties. They received emotional support from their partners, and some of them receive high amounts of emotional and practical support from family and friends. Low workplace social capital is expressed through a distant connection with the workplace and colleagues during the sickness period.

There are different reasons for the limited contact with the workplace. One was a lack of opportunities for the sick-listed women to come and visit their colleagues during working hours. Another reason was the sick-listed women's own hesitation to have contact with their workplaces during the sickness-absence period. The background for this hesitation might be conflicts in the workplace, which was sometimes also an aspect of the background for their sickness absence.

A third reason was the lack of a tradition of having contact with colleagues outside working hours. If they did not have a tradition of meeting colleagues outside working hours, it is difficult to arrange when they were sick-listed. Some of the women did not want to inform their colleagues about the background of their sickness absence. This may be interpreted as shame, especially among those with mental problems. Creating distance between themselves and their workplaces was a reaction in order to protect them from this shame.

In their situation as sick-listed, the women are vulnerable and pay extra attention to what people say when they meet with their colleagues. One woman described her experience in this way: 'There are some colleagues who have commented on my situation in a way that was hurting me.' In this woman's case, her colleagues had expressed the opinion that people can go to work even if they had some problems. She felt that they counted her among such people, and this was difficult for her to accept.

Another woman spoke about similar experiences. Her colleagues were friendly and talked to her in a kind and polite way. However, she 
sensed suspicious attitudes among some of them. This perceived lack of trust contributed to a lack of contact with colleagues and this in turn may have had a negative influence upon her efforts to return to work. To a certain degree, these women compensated for low workplace social capital with partners or close friends, or both, who helped them with daily tasks, gave them energy and comfort, and helped to build up their self-confidence. However, limited contact with the workplace contributed to a less work-oriented attitude, and probably made the road back to work longer.

\section{Low WSC and low DSC: the unconnected}

Women with both low work social capital and low domestic social capital are the most vulnerable in relation to recovery and return to work. In the sample, these were mainly single mothers. They had little support at home, some of them had a high work burden in a family with small children or children with health problems; in addition, they often had financial troubles. As single mothers, they had been in this situation for years, and there were signs of wear and tear. Often their pride prevented them from asking for help when they needed it. Isolation and lack of contact with friends, family, and colleagues were often a consequence of their lack of energy. Their struggles to cope with their home situations drained a lot of their strength and made it sometimes difficult to cope with their jobs. They felt they were expected to manage a full-time job and bear all the responsibility for their children and sometimes for their extended family. However, for some this was too much. When they were unable to cope with this situation they felt they had not been able to live up to expectations and they feel unsuccessful and lose their self-confidence.

Sick-listed single mothers were in a particularly difficult situation. They often missed having a person with whom they could share practical tasks as well as their thoughts about their actual situations and their futures. Having family members living in the neighbourhood could potentially compensate for of the role of a partner, in part. However, in this study, most of the single mothers had no family members in the neighbourhood, and they often hesitated to ask for help. They were proud and did not want to show other people that they were not coping with the situation:

I am not a person who asks for help, but I would be grateful if any one offered themselves to help. For me there is a very high

NJSR - Nordic Journal of Social Research

Vol. 6, 2015 
barrier against asking for help. I have a very high threshold to ask for help.

Some of the women had children who were grown up and had their own problems - drug abuse, eating disorders, disabilities, ME, ADHD, etc. Some of these children still lived with their mothers, and having responsibility for these children was often described as a heavy burden. However, some children could be an emotional support for their mothers in their sick-listed situations. One woman said:

I have asked my primary doctor to be sick-listed, not from my job but from my life. I feel my life is very tiresome. If I had some more help at home, I think I would function better in my job. There is a close connection between these two arenas. ... I dream of having a wife - having a man is not so necessary who could make dinner once a week, do the dishwashing, and sometimes clean the house. I think the total life situation has to be taken into consideration.

This woman's account illustrates the interplay between challenges in work and domestic situations. When the total burden is too heavy, the domestic challenges have to be prioritized. This may influence women's connections to the workplace and their reputations as stable workers. They felt it was illegitimate to use their domestic burden as an explanation for their absence from work; there was an expectation that they should be able to manage both arenas.

These women also wanted to manage both their work and their domestic demands and challenges themselves. Discussing their heavy burdens and asking for help was, for some of them, regarded as a kind of defeat. Nevertheless, this attitude also sometimes led them into isolation. The total workload took all their time. They had little time and energy for social life and therefore they were losing contact with people who could be potential helpers.

\section{Discussion: Challenges in the process of recovery and the path back to work}

In the introduction of this article, two questions were raised: 1) In what ways do work-related and domestic social capital influence the experience of being on sickness leave? and 2) in what ways do work- 
related and domestic social capital influence the prospects for returning to work? I shall now discuss these two questions.

This study shows that the basis of these women's relational social capital is in their families, in their workplaces and among their close friends, who sometimes are also their colleagues. The quality of these relationships may have an impact upon their experiences of being sick-listed and their prospects of returning to work.

\section{(1) Experiences of being on long-term sick leave}

To be long-term sick-listed is to live with uncertainty, and selfconfidence is challenged during such a period. In this situation, relational social capital is an important source of support. It is also invaluable in building self-confidence and working against feelings of shame and stigmatization. Relational social capital also contributes to emotional energy and helps to avoid isolation and sometimes depression. Having a connection to a workplace where one has positive colleagues and which gives signals that one is expected to return is of great value.

The study also shows that diagnoses have an impact on the experience of being on sick leave. Mental and musculoskeletal problems are often invisible, and they are frequently described among the diagnoses with low prestige (Album \& Westin, 2006). The invisibility of these illnesses is often a source of suspicion among people surrounding the sick-listed person. In this situation, it is important for the sick-listed individuals to have contact with people who have known them over time and accept them as hard-working persons who do not easily give up and go to their doctor to be sicklisted. The women in this sample are afraid of giving people an impression that it is easy for them to be sick-listed. They therefore need acceptance from key people in their surroundings to confirm that the negative image is not true. The reinforcement of their self-image strengthens them in their struggle to maintain their identity as working women and encourages them to fight for a return to work.

Being diagnosed as mentally ill is, for some, connected to shame (Eriksson, Starrin, Ede \& Jansson, 2011). This connection also emerges in this study. The fact that the women avoid going outdoors and meeting people may be interpreted as an aspect of this. However, a few of the women were more explicit in their descriptions of their 
shame and their fears of being unveiled as a person with mental problems. The use of a great deal of time and energy to hide their problems, both in the workplace and in their general environment, was probably an obstacle to their recovery. The reason given for this was often a desire to be accepted along with their problems, but they were afraid for their reputations and did not always expect people to be understanding.

In a Swedish study of the same diagnosis groups, Eriksson (2013) makes a distinction of four different groups. These are the returners, the ambivalent, the reoriented, and the capitulators. In my study, very few women can be included in the capitulating group. However, in relation to my study, the non-connected group corresponds most closely to the reoriented or the ambivalent. The women in the connected group most closely correspond to the returners or the ambivalent. The reasons for their ambivalence were sometimes connected to bad relations at the workplace, or they could be related to their health situation and their future ability to perform as well as before at work. This indicates that women having high workplace social capital are more inclined to return to work either to their present workplace or, if necessary, orienting towards another workplace; in women with both high domestic and high workplace social capital, the tendency is even stronger.

\section{(2) Prospects for returning to work}

Some studies have documented the significance of health-promoting factors in the workplace (Melchior et al., 2003; Oksanen et al., 2008). The connection between work-related health problems and illness, including sick leave, is also well-documented. In addition, social factors such as job control, social support from leadership or at the workplace, role conflicts, and reorganizational processes may contribute to sickness absence (Lund \& Labriola, 2009). However, in most studies, work-related illness is limited to paid work. Only in exceptional cases is the association between health, work burden, and social support in domestic life taken into consideration (StalandNyman et al., 2007; Østlund et al. 2004; Falkdal et al., 2006).

This study shows that the prospect of returning to work is influenced by relational social capital both in the workplace and in the private arena. The study indicates that many women have a satisfactory amount of social capital both in the domestic sphere and in the 
workplace. But for those with insufficient relational social capital in the workplace it is of particular importance to have adequate social capital in their private lives; similarly, those lacking domestic social capital are more dependent upon work-related social capital. In this way, insufficient social capital in the private sphere may, to a certain extent, be compensated for by sufficient social capital in the workplace, and a high amount of domestic social capital may compensate for insufficient work related social capital.

The majority of the sample interviewed in this study still identified themselves as working women and strongly desired to return to work. Therefore, there is reason to expect that a commitment to building up their social capital would be profitable for both these women and society. A lack of emotional and practical support may decrease their motivation and reduce their ability to return to work. The most vulnerable group is those who have inadequate relational social capital both in their private lives and in their workplaces. The majority of the women in this group are single mothers. They were struggling to cope with financial and practical challenges in everyday life. This caused withdrawal and sometimes a feeling of shame because they were not able to live up to the expectations they had for themselves as mothers and working women. They were in need of and wanted more support, but they got stuck into a vicious circle because their withdrawal decreased the opportunities for potential supporters. Also, other studies have shown that single mothers have both financial stress and low scores on life satisfaction and happiness (Bull \& Mittelmark, 2009), and that single women with children have a doubled risk of repeated sick leave than single women without children (Voss et al., 2008). For this group, the prospects of returning to work are dependent upon relief and support giving them a possibility to recover and return to work.

Usually the process of following up on long-term sick-listed employees in Norway focuses on facilitation in the workplace and not so much on relational aspects (Solheim \& Berg, 2012). This study shows that to succeed in the recovery process it may be important to take into consideration social relations not only in the workplace but also in the domestic sphere.

This study has identified four different groups with different levels of relational social capital. We cannot claim that the sample is representative for women on sickness absence in the two groups of diagnoses. However, the women we were able to interview represent 
some of the variations in situations for women on sick leave with these diagnoses. These representations give us valuable knowledge about how long-term sick-listed women try to combine challenges in their domestic lives and in their work lives, and the meaning of work-related and domestic social capital during the sickness-absence period.

Further research is needed to explore how these groups can improve their recovery process to make the road back to work as short as possible, and it is important to illuminate the interplay between workrelated social capital and domestic social capital. Therefore, further research is in particular required to find out what kind of help and support is required to avoid long-term sickness absence and to promote a successful rehabilitation process. By using a holistic approach and focusing on relational social capital at work and in domestic life, this study concludes that both are important for the process of returning back to work, and that neglecting the domestic sphere leads to a limited understanding of the challenges sick-listed women are struggling with.

\section{References}

Album, D. \& Westin S. (2006). Do diseases have a prestige hierarchy? A survey among physicians and medical students. Social Science \& Medicine, 66(1), 182-188.

Batt-Rawden, K. \& Solheim, L. J. (2011). Sosiale årsaker til sykefravær [Social causes of sick leave]. Report no. 13, Lillehammer: Østlandsforskning.

Berger, P., \& Luckmann, T. (1967). The social construction of reality: a treatise in the sociology of knowledge. Garden City, NY: Anchor Books.

Berkman, L. F. \& Glass, T. (2000). Social integration, social networks, social support, and health. In L. F. Berkman, \& I. Kawachi. (Eds.), Social Epidemiology (pp. 137-173). NY: Oxford University Press.

Berkman, L., \& Syme, L. (1979). Social networks, host resistance and mortality: a nine-year follow-up of Alameda County residents. American Journal of Epidemiology, 109, 186-204.

Bourdieu, P. (1986). The forms of capital. In J. G. Richardson (Ed.), Handbook of theory and research for the sociology of education (pp. 241-259). New York: Greenwood. 
Brown, G. W., \& Harris, T. (1978): Social origin of depressions: a reply. Psychological Medicine, 8(4), 577-588.

Bull, T., \& Mittelmark, M. B. (2009). Work life and mental wellbeing of single and non-single working mothers in Scandinavia. Scandinavian Journal of Public Health, 37(6), 562-568.

Campbell, C., Wood, R., \& Kelly, M. (1999). Social capital and health. London: Health Education Authority.

Charmaz, K. (2003). Grounded theory. In J. A. Smith (Ed.), Qualitative psychology: a practical guide to research methods (pp. 81-110). London: Sage Publications.

Coleman, J. S. (1988). Social capital in the creation of human capital. American Journal of Sociology, 94 (suppl.), 95-120.

Eriksson, U. B. \& Janson, S. (2013). An explorative interview study of men and women on sick leave with a musculoskeletal diagnosis seeking an acceptable life role: an explorative interview study. Nordic Journal of Social Research. Vol. 4.

Eriksson, M. (2011). Social capital and health - implications for health promotion. Global Health Action, 8(4), 5611. doi:10.3402/gha.v410.5611

Eriksson, M., Ng, N., Weinehall, L., \& Emmelin, M. (2011). The importance of gender and conceptualization for understanding the association between collective social capital and health: a multilevel analysis from northern Sweden. Social Science \& Medicine. 73(2), 264-73.

Eriksson, U. B., Starrin, B., Ede, L., \& Janson S. (2011). Social bonds, emotional processes and mental health. In H. Nordby, R. Rønning \& G. Tellnes (Eds), Social aspects of illness, disease and sickness absence (pp. 131-154). Oslo: Uniped.

Eriksson, M., L. Dahlgren, U. Janlert, L. Weinehall \& M. Emmelin. (2010). Social capital, gender, and educational level - impact on self-rated health. The Open Public Health Journal, 3, 1-12. doi:10.2174/1874944501003010001

Esser, H. (2008). The two meanings of social capital. In D. Castiglione, J. W. Van Deth, \& W. Guglielmo (Eds.), The handbook of social capital (pp. 22-49). Oxford: Oxford University Press.

Falkdal , A. H., Edlund, C. \& Dahlgren, L. (2006). Experiences within the process of sick leave. Scandinavian Journal of Occupational Therapy, 13(3), 17-182. 
Gannik, D. E. (2005). Social sygdomsteori: et situationelt perspektiv [Social sickness theory: a situational perspective]. Frederiksberg: Forlaget Samfundslitteratur.

Garret-Peters, R. (2009). 'If I don't have to work anymore, who am I?' Job loss and collaborative self-concept repair. Journal of Contemporary Ethnography, 38(5), 547-583

Glasser, B. \& Strauss, A. (1967). The discovery of grounded theory: strategies for qualitative research. Chicago: Aldine.

Glasser, B. (1998). Doing grounded theory. Mill Valley, CA: Sociology Press

Goffman, E. (1961). Asylums. New York: Doubleday.

Hyyppä, M. T. \& J. Mäki. (2001). Individual-level relationships between social capital and self-rated health in a bilingual community. Preventative Medicine, 32(2), 148-155.

Hyyppä, M. T. \& J. Mäki. (2003). Social participation and health in a community rich in stock of social capital. Health Education Research, 18(6), $770-779$.

Järvinen, M., \& Mik-Meyer, N. (Eds.) (2003). At skabe en klient [Creating a client]. København: Hans Reitzels Forlag.

Kawachi, I., Subramanian, S. V., \& Kim, D. (2008). Social capital and health: a decade of progress and beyond. In I. Kawachi, S. V. Subramanian, \& D. Kim (Eds.), Social capital and health (pp. 1-26). NY: Springer.

Kim, D., Subramanian, S.V., \& Kawachi I. (2008). Social capital and physical health: a systematic review of the literature. In I. Kawachi I, S. V. Subramanian, \& D. Kim (Eds), Social capital and health (pp. 139-90). NY: Springer.

Liukkonen, V., Virtanen P., Kiwimäki M., Pentti J., \& Vahtera J. (2004). Social capital in working life and the health of employees. Social Science \& Medicine, 59(12), 2447-2458.

Lockner , K. A., Kawacki, I., Brennan, R.T. \& Buka, S.L. (2003). Social capital and neighborhood mortality rates in Chicago. Social Science \& Medicine, 56(8), 1797-1805.

Lomas, J. (1999). Social capital and health: Implications for public health and epidemiology. Social Sciences \& Medicine, 47(9), 1181-1188.

Lund T., \& Labriola, M. (2009). Sickness absence in Denmark - research, results and reflections. Scandinavian Journal of Work, Environmental \& Health, Supplements 7, 5-14. 
Mamun, A. A., Clavarino, A. M., Najman J. M., Williams, G. M., O’Callaghan, M. J., \& Bor, W. (2009). Journal of Women's Health, 18(12), 20232031. doi:10.1089/jwh.2008.1050.

Melchior, M., Niedhammer, I., Berkman, L.F. \& Goldberg, M. (2003). Do psychosocial work factors and social relations exert independent effects on sickness absence? A six-year prospective study of the GAZEL cohort. Journal of Epidemiology \& Community Health, 57(4), 285-293.

Nyqvist, F., F. Finnas, G. Jakobsson \& S. Koskinen. (2008). The effect of social capital on health: the case of two language groups in Finland. Health Place, 14(2), 347-360.

Ockander , M. \& Timpka, T. (2003). Women's experiences of long-term sickness absence: implications for rehabilitation practice and theory. Scandinavian Journal of Public Health, 31(2), 143-148.

Oksanen, T., Kouvonen, A., Kiwimäki, M., Pentti, J., Virtanen, M., Linna, A., \& Vahtera, J. (2008). Social capital at work as a predictor of employee health: multilevel evidence from work units in Finland. Social Science \& Medicine, 66(3), 637-649.

Portes, A. (1998). Social capital: its origins and applications in modern sociology. Annual Review of Sociology, 24, 1-24.

Putnam, R. D. (2000). Bowling alone: the collapse and revival of American community. New York: Simon \& Schuster.

Putnam R. D. (1993). Making democracy work: civic traditions in modern Italy. Princeton NJ: Princeton University Press.

Rose, R. (2000). How much does social capital add to individual health? A survey study of Russia. Social Science \& Medicine, 51(9), 1421-1435.

Rønning, R. (2011). Sickness absence as a social construction: A theoretical perspective. In H. Nordby, R. Rønning, \& G. Tellnes (Eds.), Social aspects of illness, disease and sickness absence (pp. 63-82). Oslo: Unipub.

Solheim, L. J. (2011). The understanding of Norwegian women's sickness absence: towards a holistic approach? Nordic Journal of Social Research, Vol. 2

Solheim, L. J. \& Berg, A. M. (2012). Godvilje i motvind? Om inkluderende arbeidsliv i statlige virksomheter. [Goodwill in decline? Inclusive Working Life in State Enterprises]. Research report no. 151, Lillehammer: Lillehammer University College. 
Staland-Nyman, C., Alexanderson K., \& Hensing, G. (2008). Associations between strain in domestic work and self-rated health: a study of employed women in Sweden. Scandinavian Journal of Public Health, $36(1), 21-27$.

Steihaug, S. (2007). Women's strategies for handling chronic muscle pain: a qualitative study. Scandinavian Journal of Primary Health Care, 25(1), 44-48.

Turner, B. (2003). Social Capital, Inequality and Health: The Durkheimian Revival. Social Theory and Health, 1(1), 4-20.

Verhaeghe, P. P., E. Pattyn, P. Bracke, M. Verhaeghe \& B. Van De Putte (2012). The association between network social capital and self-rated health: pouring old wine in new bottles? Health Place, 18(2), 358-365.

Verdonk, P., de Rijk, A., Klinge, I., \& De Vries, A. (2008). Sickness absence as an interactive process: Gendered experiences of young highly educated women with mental health problems. Patient Education and Counseling, 73(2), 300-306

Voss, M., Josephson, M., Stark S., Vaez, M., Alexanderson K., Alfredsson L., \& Vingård, E. (2008). The influence of household work and of having children on sickness absence among publicly employed women in Sweden. Scandinavian Journal of Public Health, 36(6) 564-572

Wolf, S. \& Bruhn, J. (1998). The power of clan. New Brunswick: Transaction Publishers.

Woolcock, M. (2001). The place of social capital in understanding social and economic outcomes. Canadian Journal of Policy Research, 2(1), 1177.

Östlund, G., Cederlund, E., Hensing, G., \& Alexanderson, K. (2004). Domestic strain: a hindrance to rehabilitation? Scandinavian Journal of Caring Science, 18(1), 49-56. 